\title{
Impact of air pollution on pregnancy duration, birth outcomes and children's health: Polish Mother and Child Cohort
}

\author{
K. Polańska ${ }^{1}$, M. Kowalska ${ }^{2} \&$ W. Hanke ${ }^{1}$ \\ ${ }^{I}$ Department of Environmental Epidemiology, \\ Nofer Institute of Occupational Medicine, Poland \\ ${ }^{2}$ Department of Epidemiology, Medical Faculty, \\ Medical University of Silesia, Poland
}

\begin{abstract}
The aim of this study was to evaluate the association between exposure to ambient air pollution and pregnancy duration, birth outcomes and children's health.

The study was based on the data collected within the Polish Mother and Child Cohort (REPRO_PL). The analysis of $\mathrm{PM}_{10}$ impact on birth outcomes and children's health was restricted to 920 mother-child pairs. Daily PM $_{10}$ exposure was calculated according to a predictive model in which the following variables were included: district, distance between place of residence and main road, house density, linear, quadratic, cubic trends and cyclic time trends.

The average value of daily $\mathrm{PM}_{10}$ concentration in ambient air was $32 \mu \mathrm{g} / \mathrm{m}^{3}$. The association between $\mathrm{PM}_{10}$ concentration in the second trimester of pregnancy and birth length was of borderline significance $(\mathrm{p}=0.06)$. The other assessments based on REPRO_PL cohort confirmed statistically significant relationship between PAH metabolites and cotinine level in pregnancy and the child cephalization index $(\mathrm{p}=0.04)$. Higher prenatal PAH metabolite concentrations increased the risk of more frequent ( $\geq 1$ /year) respiratory infections in children during the first year of life.

Presented study provides evidence that $\mathrm{PM}_{10}$ and $\mathrm{PAH}$ exposure in pregnancy might adversely affect fetal development and children's health.

Keywords: PM 10 , birth outcomes, gestational age, children's health, cohort study.
\end{abstract}




\section{Introduction}

Nowadays, special attention is paid to the impact of air pollution on birth outcomes and children's health. Although, a growing number of studies in this field exist, their results are not fully consistent, with some studies indicating that prenatal exposure to air pollution could be a risk factor for shortened pregnancy duration (or preterm delivery), decreased birth weight (or low birth weight), and other adverse health effects [1-7]. During prenatal period there are critical windows for the development of organs in which exposure, at the level that is not dangerous for adults, may adversely affect morphologies and functioning of the systems. In addition, reduction in fetal growth has been indicated to predict the occurrence of diseases and neurodevelopment delay later in life [8].

\section{The aim of study}

The aim of this study was to assess the impact of exposure to air pollution on pregnancy duration and birth outcomes based on the Polish Mother and Child Cohort Study (REPRO_PL cohort). In addition the impact of air pollution on children's health, based on REPRO_PL cohort, has been discussed.

\section{Material and methods}

The study was based on data from the REPRO_PL cohort. The mothers' recruitment and follow-up procedures have been published previously [9]. The analysis was restricted to 920 mother-child pairs and the approval of the Ethical Committee of the Nofer Institute of Occupational Medicine was obtained. Information about the postal address of subjects was collected three times during pregnancy (8th-12th; 20th-24th; 30th-34th week of gestation) and, moreover, within a week after delivery. Any address changes were noticed and included in the analysis. Based on this information, a daily $\mathrm{PM}_{10}$ level during pregnancy was assigned to each woman using predictive modelling. The model included the following variables: voivodeship (administrative subdivision of Poland, corresponding to district or province), distance from the main road, house density based on the CORINE Land Cover 2006 [10], days of exposure (linear, quadratic, cubic trends) and cyclic time trends ( $\sin$ and cos functions with periods from 1 year to 3 months). Daily concentrations of $\mathrm{PM}_{10}$ were extracted from AirBase V6 [11]. The average exposure for the whole pregnancy period as well as for each trimester of pregnancy was calculated.

Birth outcomes were measured by a nurse who assisted the birth and included: weight (BW), length (BL) and head circumference (HC). In addition, ponderal index (PI) $\left[\mathrm{BW}(\mathrm{g}) \times 10^{2} /(\mathrm{BL}(\mathrm{cm}))^{3}\right]$ and cephalization index (CI) $\left[\mathrm{HC}(\mathrm{cm}) \times 10^{4} / \mathrm{BW}(\mathrm{g})\right]$ were calculated [12]. Pregnancy duration was estimated using the date of the last menstrual period. Moreover, mothers filled in a detailed questionnaire concerning socio-demographic characteristics (age, marital status, parity, maternal education, employment), medical history, previous and current pregnancies and lifestyle variables (smoking, alcohol consumption during 
pregnancy, pre-pregnancy weight and height, weight gain in pregnancy). Body mass index (BMI) and gestational weight gain were further classified using the existing guidelines $[13,14]$. Information concerning active and passive smoking was verified by the cotinine level in saliva collected in the third trimester of pregnancy. The cotinine level was measured by LC-ESI-MS/MS method as described by Stragierowicz et al. [15].

The statistical analyses were performed using R 3.0.1 package. Categorical data were presented as numbers and frequencies (\%), and continuous data were expressed as mean value and percentiles. First we determined parental and pregnancy factors associated with birth outcomes. Next step was to assess the relationship between exposure to $\mathrm{PM}_{10}$ (for whole pregnancy and for each trimester of pregnancy) and birth outcomes by means of the linear regression in two models (to avoid excessive influence of extreme values, robust methods were applied). In the first model we controlled a child gender and gestational age as confounders; in the second we controlled all confounders obtained in the multivariate analysis (determinants in the model were chosen according to criterion $\mathrm{p}<0.1)$. Estimates are expressed as a change in birth outcomes for a $10 \mu \mathrm{g} / \mathrm{m}^{3}$ increase in the mean $\mathrm{PM}_{10}$ levels at each woman's residence during the corresponding period.

\section{Results}

Basic descriptive data of birth outcomes are shown in Table 1. On average the children were born at the 39.5 th week of gestation ( \pm 1.5 week) with the mean birth weight of $3396 \mathrm{~g} \mathrm{(} \pm 460 \mathrm{~g})$. Of all the births, $1.9 \%$ were classified as term with low birth weight (birth weight $<2500 \mathrm{~g}$ and at gestational age $\geq 37$ weeks).

Table 1: Descriptive statistics of the pregnancy duration and newborns' anthropometric indicators.

\begin{tabular}{|l|c|c|c|c|}
\hline Birth outcomes & Mean & \pm SD & Median & Range \\
\hline Gestational age [weeeks] N=920 & 39.5 & 1.5 & 39.6 & $28.7-43.4$ \\
\hline Birth weight $[\mathrm{g}] \mathrm{N}=920$ & 3396.0 & 460.2 & 3403.0 & $2150.0-5100.0$ \\
\hline Birth length [cm] N=918 & 55.00 & 2.8 & 55.2 & $48.0-64.00$ \\
\hline Head circumference [cm] N=918 & 34.00 & 1.6 & 34.3 & $31.0-39.00$ \\
\hline Ponderal index [g/cm 3 ] N=918 & 2.02 & 0.2 & 2.0 & $1.5-2.81$ \\
\hline Cephalisation index [cm/g] N=918 & 100.5 & 12.2 & 101.9 & $74.5-148.8$ \\
\hline
\end{tabular}

Table 2 presents results of multivariate analysis of the relationship between birth outcomes and selected factors describing pregnancy, mothers and children. About $30 \%$ of the women were older than 30 , majority of mothers were married $(78 \%)$ and $58 \%$ had no children prior to the current pregnancy. The recommended level of gestational weight gain was achieved by $50 \%$ of the study participants. About $10 \%$ of women consumed alcohol at least once per month in the pregnancy period, and $14 \%$ were classified as smokers. Primiparous mothers, those with low weight gain in pregnancy and smokers had newborns with a lower birth weight $(\mathrm{p}<0.001)$. Mothers who were taller had bigger and longer babies $(\mathrm{p} \leq 0.02)$. Girls 


\begin{tabular}{|c|c|c|c|c|c|c|c|}
\hline \multirow{6}{*}{ 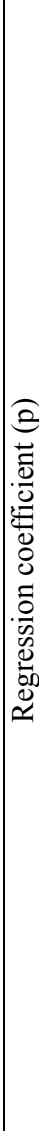 } & $\Xi$ & 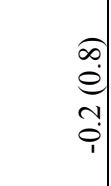 & $\begin{array}{l}\stackrel{f}{\sigma} \\
\stackrel{0}{0} \\
0\end{array}$ & $\begin{array}{ll}\tilde{n} & 0 \\
\mathfrak{n} & 0 \\
0 & 0 \\
0 & ? \\
0 & 1\end{array}$ & $\begin{array}{l}n \\
\mathfrak{n} \\
\infty \\
0 \\
i\end{array}$ & 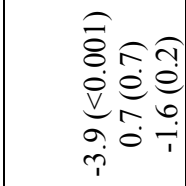 & $\begin{array}{l}\text { J } \\
8 \\
0 \\
0 \\
\infty \\
\text { i }\end{array}$ \\
\hline & $\bar{\Omega}$ & $\begin{array}{l}0 \\
0 \\
0 \\
0 \\
0 \\
0 \\
1\end{array}$ & $\begin{array}{l}\hat{\sigma} \\
\hat{e} \\
\overrightarrow{8} \\
\dot{0}\end{array}$ & $\begin{array}{cc}\infty & \hat{0} \\
\dot{e} & 0 \\
\overline{0} & \overline{0} \\
0 & 0 \\
0 & 0\end{array}$ & 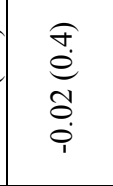 & 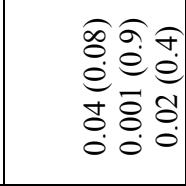 & 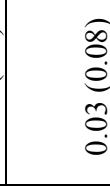 \\
\hline & $\underset{I}{\mathcal{U}}$ & $\begin{array}{c}\tilde{n} \\
e \\
\tilde{e} \\
\vdots\end{array}$ & $\begin{array}{c}\hat{E} \\
\stackrel{0}{e} \\
\dot{0}\end{array}$ & 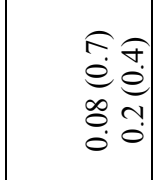 & 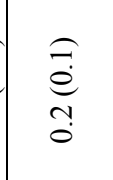 & 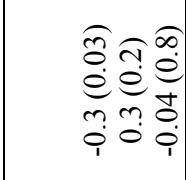 & 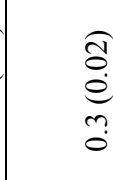 \\
\hline & $\vec{n}$ & 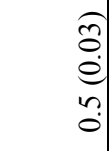 & 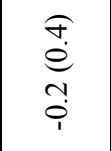 & 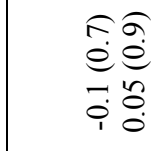 & 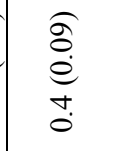 & 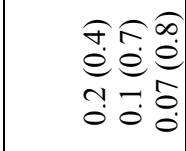 & 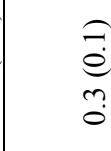 \\
\hline & 童 & $\begin{array}{l}6 \\
\dot{0} \\
\vdots \\
\vdots \\
-\end{array}$ & $\begin{array}{l}\stackrel{f}{\sigma} \\
e \\
0 \\
\dot{0} \\
i\end{array}$ & 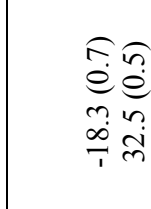 & 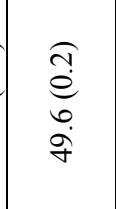 & 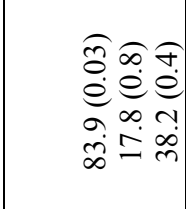 & 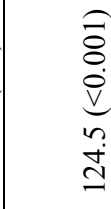 \\
\hline & 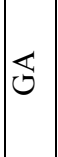 & $\begin{array}{l}\widehat{c} \\
e \\
v \\
0 \\
1\end{array}$ & $\begin{array}{l}\hat{n} \\
e \\
o \\
o \\
\dot{0}\end{array}$ & \begin{tabular}{ll}
\multirow{1}{*}{} & 0 \\
$e$ & 0 \\
$e$ & 0 \\
ํ. & 0 \\
0 & 0
\end{tabular} & 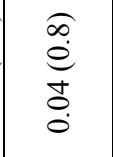 & 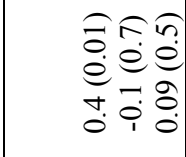 & $\begin{array}{l}n \\
0 \\
\infty \\
\infty \\
0 \\
0\end{array}$ \\
\hline 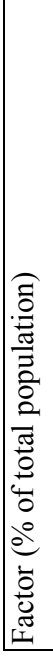 & & 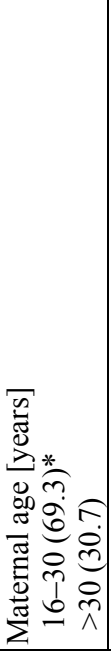 & 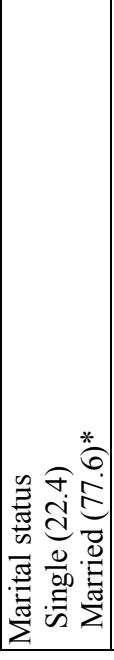 & 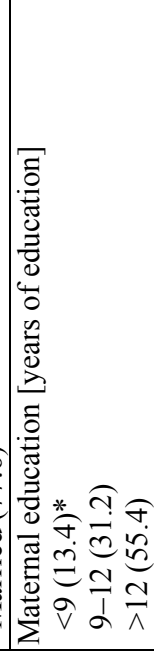 & 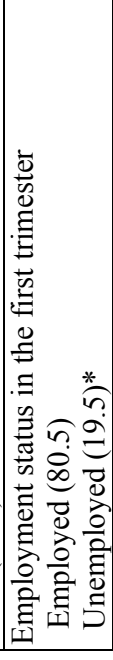 & 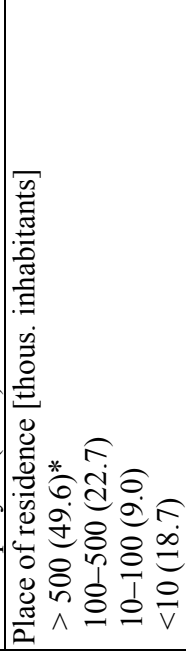 & 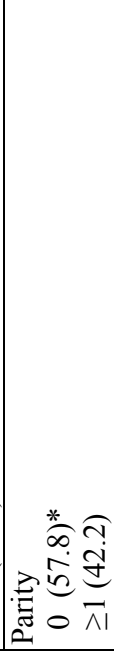 \\
\hline
\end{tabular}




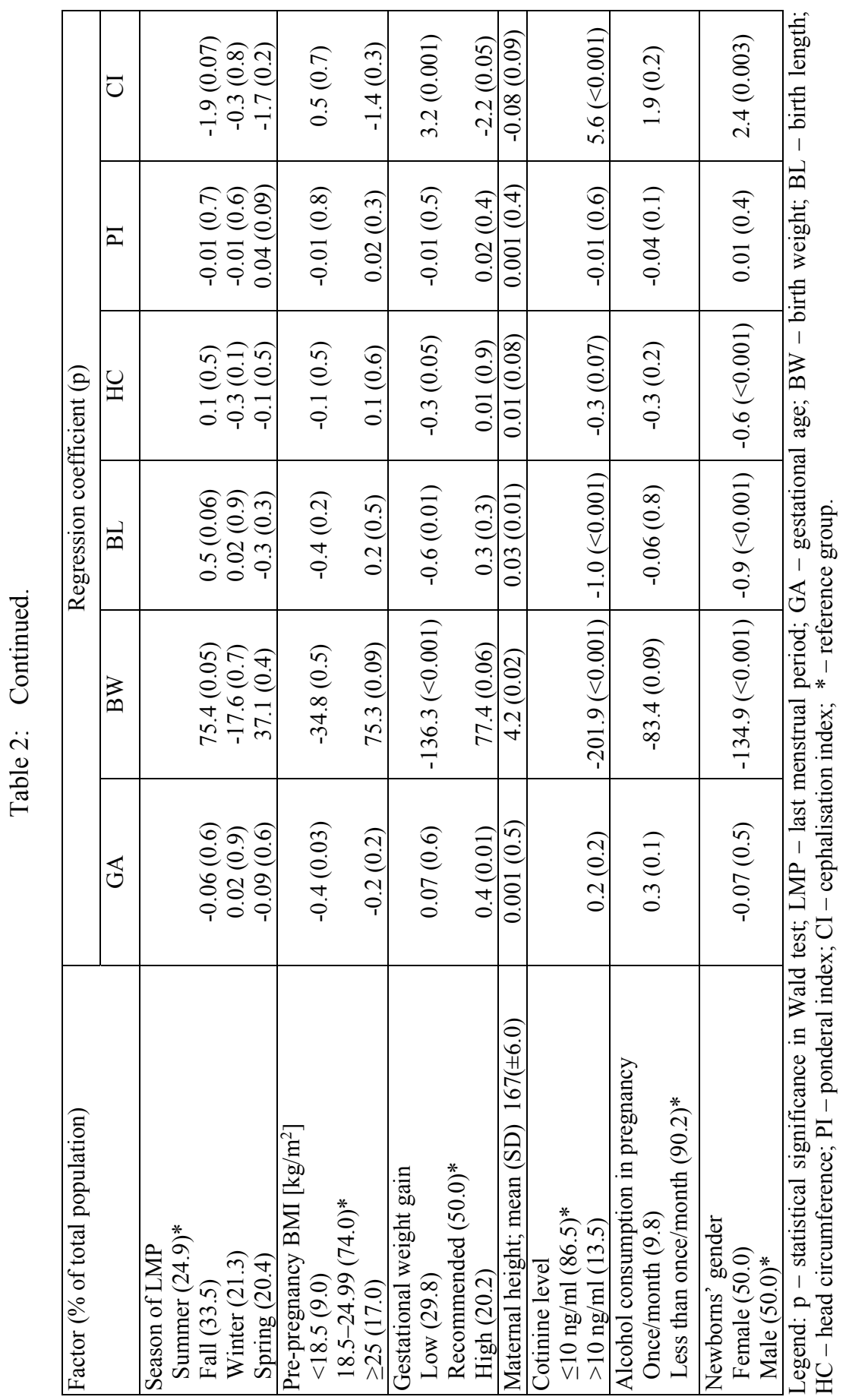


weighed less, were smaller and had smaller head circumference compared to boys $(\mathrm{p}<0.001)$. Shortened gestational age was associated with pre-pregnancy underweight $(p \leq 0.03)$, whereas longer pregnancy duration was observed for the women with high weight gain in pregnancy $(\mathrm{p}=0.01)$.

Characteristics of exposure variables are presented in Table 3. The mean residential outdoor $\mathrm{PM}_{10}$ level was $32 \mu \mathrm{g} / \mathrm{m}^{3}$. In the case of $38 \%$ of the women, $\mathrm{PM}_{10}$ concentrations exceeded WHO limit values [16] on at least 35 days during pregnancy period. Individual $\mathrm{PM}_{10}$ levels for each trimester were well correlated with $\mathrm{PM}_{10}$ levels for the whole pregnancy (correlation coefficients ranging from $\mathrm{r}=0.5$ to $\mathrm{r}=0.8 ; \mathrm{p}<0.001$ ), and slightly between themselves (with correlation coefficients ranging from $\mathrm{r}=0.2$ to $\mathrm{r}=0.3 ; \mathrm{p}<0.001$ ).

Table 3: Descriptive statistics of individual exposure to $\mathrm{PM}_{10}$ during different pregnancy periods and the relation between total and partial exposure.

\begin{tabular}{|c|c|c|c|c|c|c|c|c|}
\hline \multirow[t]{2}{*}{$\begin{array}{l}\text { Pregnancy } \\
\text { period }\end{array}$} & \multirow{2}{*}{$\begin{array}{c}\text { Mean } \\
(\mathrm{SD}) \\
{\left[\mu \mathrm{g} / \mathrm{m}^{3}\right]}\end{array}$} & \multicolumn{3}{|c|}{ Percentiles $\left[\mu \mathrm{g} / \mathrm{m}^{3}\right]$} & \multirow[b]{2}{*}{ Range } & \multicolumn{3}{|c|}{$\begin{array}{c}\text { Pearson's correlation } \\
\text { coefficient }\end{array}$} \\
\hline & & 25 & 50 & 75 & & $\begin{array}{c}1 \mathrm{st} \\
\text { trimester }\end{array}$ & $\begin{array}{c}\text { 2nd } \\
\text { trimester }\end{array}$ & $\begin{array}{c}\text { 3rd } \\
\text { trimester }\end{array}$ \\
\hline $\begin{array}{l}1 \text { st } \\
\text { trimester }\end{array}$ & $\begin{array}{l}31.3 \\
(9.6)\end{array}$ & 24.4 & 30.8 & 38.3 & $8.4-58.7$ & & & \\
\hline $\begin{array}{l}\text { 2nd } \\
\text { trimester }\end{array}$ & $\begin{array}{l}32.5 \\
(9.5)\end{array}$ & 26.1 & 33.1 & 39.3 & $8.0-57.1$ & $0.3^{*}$ & & \\
\hline $\begin{array}{l}\text { 3rd } \\
\text { trimester }\end{array}$ & $\begin{array}{l}30.7 \\
(11.1)\end{array}$ & 22.1 & 30.0 & 38.2 & $8.1-61.7$ & $-0.2 *$ & $0.3^{*}$ & \\
\hline $\begin{array}{l}\text { Whole } \\
\text { pregnancy }\end{array}$ & $\begin{array}{l}31.5 \\
6.4)\end{array}$ & 27.1 & 31.4 & 36.2 & $14.8-49.2$ & $0.5^{*}$ & $0.8^{*}$ & $0.6^{*}$ \\
\hline
\end{tabular}

Table 4 presents results of $\mathrm{PM}_{10}$ exposure impact on pregnancy duration, and birth outcomes. The analysis indicated a statistically significant negative relationship between $\mathrm{PM}_{10}$ exposure and birth length (Model 1). This association was significant for the second, third trimester and the whole pregnancy period $(\beta=-0.01 ; \mathrm{p}=0.04 ; \quad \beta=-0.02 ; \mathrm{p}=0.02 ; \beta=-0.02 ; \mathrm{p}=0.03$ respectively $)$. After adjustment for potential confounders the same pattern persisted (Model 2) - the results were of borderline significance for the second trimester of pregnancy $(\beta=-0.02 ; p=0.06)$. For other periods as well as for the whole pregnancy regression coefficients were not statistically significant. Model 1 was adjusted for gestational age (except for model for gestational age) and neonate gender, Model 2 was adjusted for all confounders. 


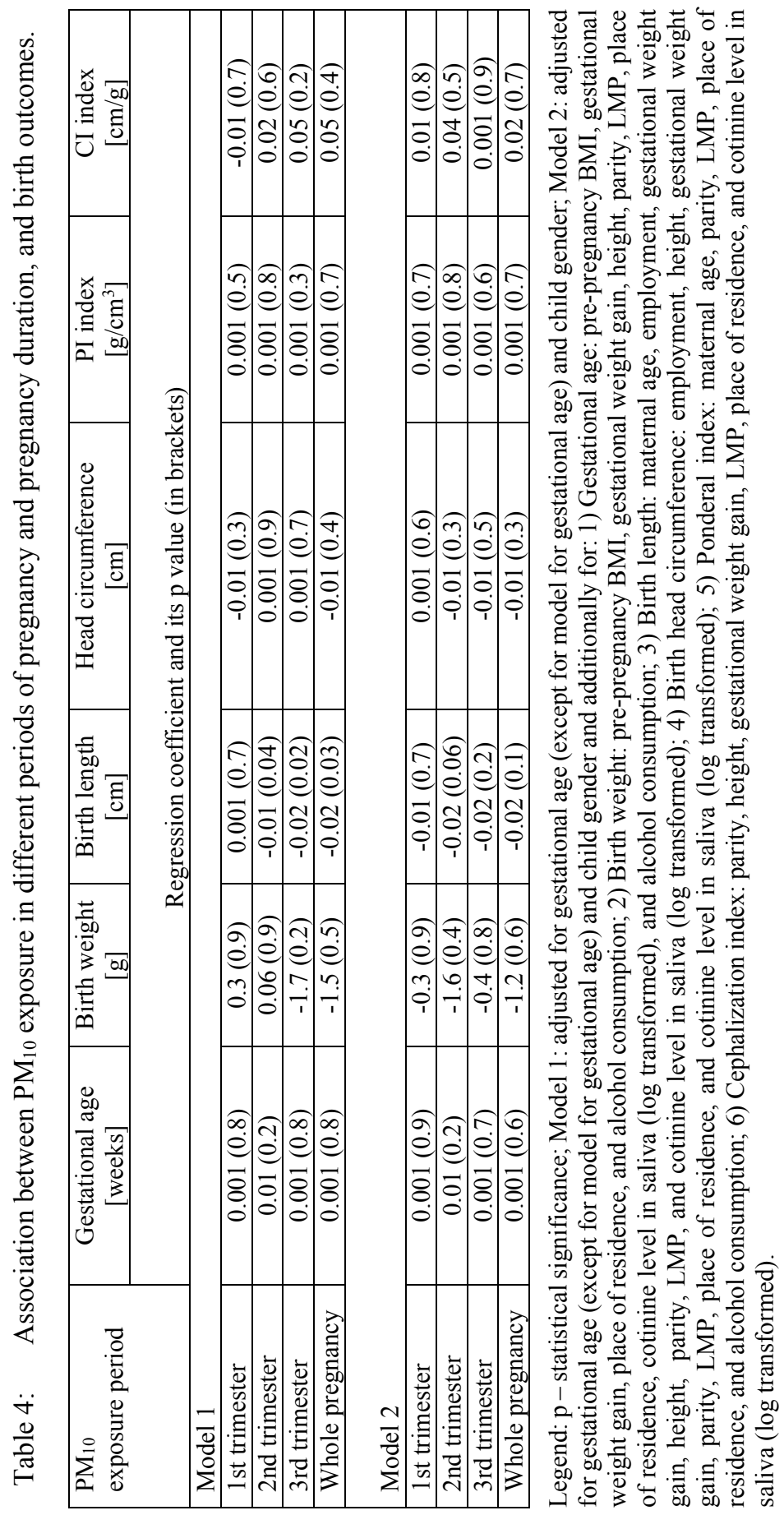




\section{Discussion}

Findings from the REPRO_PL cohort suggest that prenatal exposure to outdoor air pollution, expressed by $\mathrm{PM}_{10}$ concentration, affects birth outcomes, especially by reducing child length.

The results of some studies evaluating the impact of air pollution (with the measurement of different pollutants, by means of different methods of exposure assessment and using different study design) on pregnancy duration and birth outcomes are mixed and inconclusive, although some of them indicate that such associations exist. The analysis, as the part of European Study of Cohorts for Air Pollution Effects (ESCAPE), based on data from 14 population-based mother and child cohort studies indicated that $\mathrm{PM}_{10}$ concentrations were higher in central and southern countries than in northern ones (with mean $\mathrm{PM}_{10}$ concentration during pregnancy for pooled cohort equal $25.4 \mu \mathrm{g} / \mathrm{m}^{3}$ as lower than noted in REPRO_PL cohort) [4]. The other observation made by The International Collaboration on Air Pollution and Pregnancy Outcomes (ICAPPO) showed that median $\mathrm{PM}_{10}$ concentrations in the Generation R study (the Netherlands) was similar to, and in the EDEN cohort (France) was lower than noted for the REPRO_PL cohort $[2,3]$. Based on the ESCAPE assessment $16 \%$ increase in risk of low birthweight at term was associated with an increase of $\mathrm{PM}_{10}$ exposure by $10 \mu \mathrm{g} / \mathrm{m}^{3}$ [4]. In analysis made by ICAPPO group the risk of low birthweight associated with a $10 \mu \mathrm{g} / \mathrm{m}^{3}$ increase in average $\mathrm{PM}_{10}$ concentration during pregnancy ranged from $0.63(95 \%$ CI 0.3-1.4) in the Netherlands, and to 1.2 (95\% CI 0.6-2.2) in Vancouver, with 6 research groups (out of 13) reporting statistically significant adverse associations [2]. After controlling for socioeconomic status, the reduction in mean birth weight associated with $\mathrm{PM}_{10}$ increase of $10 \mu \mathrm{g} / \mathrm{m}^{3}$ ranged from 2 to $20 \mathrm{~g}$ for most of locations. In fully adjusted random-effects meta-analyses a $10 \mu \mathrm{g} / \mathrm{m}^{3}$ increase in $\mathrm{PM}_{10}$ was associated with decreased term birthweight $(-8.9 \mathrm{~g} ; 95 \% \mathrm{CI}-13.2$ to -4.6$)$ [3]. Similarly to our analysis, but based on $\mathrm{NO}_{2}$ concentration in ambient air, results of the Ballester study revealed that pollution was associated with change in birth length of $-0.3 \mathrm{~cm}(95 \% \mathrm{CI}-0.5$ to -0.03$)$ [17].

Our study has several limitations. Firstly, the number of women included in the study is rather small compared with that in other studies. Large sample size can be achieved in cross-sectional studies, however, this approach has several limitations mostly related to exposure misclassification and lack of data about confounding factors. Secondly, we had no data on other pollutants $\left(\mathrm{PM}_{2.5}, \mathrm{SO}_{2}, \mathrm{CO}, \mathrm{NO}_{2}\right)$ for which some associations with pregnancy duration and birth outcomes have been identified. Consequently we cannot affirm that $\mathrm{PM}_{10}$ is the pollutant component associated with the outcomes measured or a proxy for other toxicants. In addition, we did not have information on the indoor levels of air quality. However, the ETS exposure as an important source of indoor air pollution was controlled for. Finally, the exposure assessment created several limitations of the study. We assessed $\mathrm{PM}_{10}$ levels by considering place of residence of each participant; however the individual's precise exposure to air pollution would be expected to depend on pregnant women's location and activity patterns. We speculate that most study 
subjects spend the majority of time in their residential area (the majority of women in this cohort discontinue working activity in early pregnancy). An additional limitation related to exposure assessment is created by the fact that we were not able to perform dispersion modelling or land use regression. Notwithstanding the aforementioned weaknesses our study has several important strengths. In this prospective study we followed pregnant women from early pregnancy and assessed exposure, health outcomes and covariates with great detail. In our analysis we had access to accurate information about each woman's residence throughout pregnancy including changes of the postal address. In addition, we have included into the REPRO_PL cohort healthy women without any suspicion of pregnancy complications at enrolment into the study which minimize the impact of such conditions on outcomes of interest.

Results of several analyses performed based on a subsample of REPRO_PL, concerning the prenatal exposure to polycyclic aromatic hydrocarbons (PAH) (based on variety of metabolites) and its impact on pregnancy outcomes and children's health were published earlier [17-20]. Those analyses in consistency to $\mathrm{PM}_{10}$ assessment indicate that Polish pregnant women suffer from a higher PAH exposure level than those in other western countries with living in the city centres, usage of coal for residential heating and passive smoking as significant predictors of PAH metabolites [18]. Statistically significant association was found between the sum of 1-,2-,3-,4-, and 9- hydroxyphenanthrene along with cotinine level and the cephalization index $(p=0.04)$ [19]. Increased cephalization index, the ratio of head size to birth weight, may suggest that growth restriction might induce a "brain-sparing" process at developmental expense of other organs. This could be a particular concern taking into account that children born with a larger head circumference relative to the body weight score are significantly lower in neurodevelopmental tests (IQ) and school performance and have a higher risk of subsequent morbidity and mortality. Our other assessment indicated, although not statistically significant (taking into account power limitations) a negative association between 1-hydroxypyrene and child psychomotor development [20]. Finally, the higher 1-hydroxypyrene concentrations in urine increased the risk of more frequent $(\geq 1 /$ year) respiratory infections in children during the first year of life (data not yet published).

The study findings indicate that prenatal exposure to air pollution measured by $\mathrm{PM}_{10}$ concentration may reduce child length. Taking into account a rather high level of exposure to air pollution in our study population, its adverse effects observed in our analysis and in other studies, as well as indicated long-term consequences of such exposure, strategies to reduce air pollution should be developed and enforced so as to prevent risk to child health and development.

\section{References}

[1] Woodruff, T.J., Parker J.D., Darrow L.A., Slama R., et al. Methodological issues in studies of air pollution and reproductive health. Environ Res, 109(3), pp. 311-320, 2009. 
[2] Parker J.D., Rich D.Q., Glinianaia S.V., Leem L.H., et al. The international collaboration on air pollution and pregnancy outcomes: initial results. Environ Health Perspect, 119(7), pp. 1023-1028, 2011.

[3] Dadvand P., Parker J., Bell M.L., Bonzini M., et al. Maternal exposure to particulate air pollution and term birth weight: a multi-country evaluation of effect and heterogeneity. Environ Health Perspect, 121(3), pp. 267-373, 2013.

[4] Pedersen M., Giorgis-Allemand L., Bernard C., Aguilera I., et al. Ambient air pollution and low birthweight: a European cohort study (ESCAPE). Lancet Respir Med, 1(9), pp. 695-704, 2013.

[5] Proietti E., Röösli M., Frey U. \& Latzin P. Air pollution during pregnancy and neonatal outcome: a review. J Aerosol Med Pulm. Drug Deliv, 26(1), pp. 9-23, 2013.

[6] Stieb D.M., Chen L., Eshoul M. \& Judek S. Ambient air pollution, birth weight and preterm birth: a systematic review and meta-analysis. Environ Res, 117, pp. 100-11, 2012.

[7] Guxens M., Garcia-Esteban R., Giorgis-Allemand L., Forns J., et al. Air pollution during pregnancy and childhood cognitive and psychomotor development: six European birth cohorts. Epidemiology, 25(5), pp. 636-47, 2014.

[8] Silveira P.P., Portella A.K., Goldani M.Z. \& Barbieri M.A. Developmental origins of health and disease (DOHaD). J Pediatr, 83(6), pp. 494-504, 2007.

[9] Polańska K., Hanke W., Gromadzińska J., Ligocka D., et al. Polish mother and child cohort study - defining the problem, the aim of the study and methodological assumptions. IJOMEH, 22(4), pp. 383-391, 2009.

[10] CORINE Land Cover (CLC, 2006). Online. http://clc.gios.gov.pl/

[11] The European Air quality database. Online. http://www.eea.europa.eu/ data-and-maps/data/airbase-the-european-air-quality-database-8\#tab-databy-country

[12] Choi H., Rauh V., Garfinkel R., Tu Y. \& Perera F.P. Prenatal exposure to airborne polycyclic aromatic hydrocarbons and risk of intrauterine growth restriction. Environmental Health Perspectives, 116(5), pp. 658-665, 2008.

[13] WHO BMI classification. Online. http://apps.who.int/bmi/index.jsp? introPage=intro_3.html

[14] Abrams B., \& Altman S.L., \& Pickett K.E. Pregnancy weight gain: still controversial. Am J Clin Nutr, 71 (5 Suppl), pp. 1233S-1241S, 2000.

[15] Stragierowicz J., Mikołajewska K., Zawadzka-Stolarz M., Polańska K. \& Ligocka D. Estimation of cutoff values of cotinine in urine and saliva for pregnant women in Poland. BioMed Research International art. 386784, 2013.

[16] WHO Air quality guidelines for particulate matter, ozone, nitrogen dioxide and sulfur dioxide - Global update 2005 - Summary of risk assessment. Online. http://www.who.int/phe/health_topics/outdoorair/outdoorair_aqg /en 
[17] Ballester F., Estarlich M., Iñiguez C., Llop S., et al. Air pollution exposure during pregnancy and reduced birth size: a prospective birth cohort study in Valencia, Spain. Environ Health, 9, 6, 2010.

[18] Polańska K., Hanke W., Dettbarn G., Sobala W., et al. The determination of polycyclic aromatic hydrocarbons in the urine of non-smoking Polish pregnant women. Science of the Total Environment; 487, pp. 102-109, 2014

[19] Polańska K., Dettbarn G., Jurewicz J., Sobala W., et al. Effect of Prenatal Polycyclic Aromatic Hydrocarbons Exposure on Birth Outcomes: The Polish Mother and Child Cohort Study. BioMed Research International art. 408939, 2014.

[20] Polańska K., Hanke W., Sobala W., Trzcinka-Ochocka M., et al. Developmental effects of exposures to environmental factors: The Polish Mother and Child Cohort Study. BioMed Research International art. 629716, 2013. 